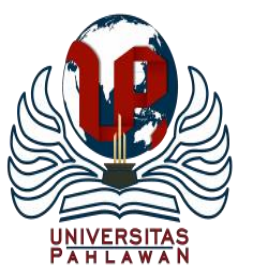

Jurnal Basicedu Volume 4 Nomor 4 Tahun 2020 Halm. 813 - 820

JURNAL BASICEDU

Research \& Learning in Elementary Education

https://jbasic.org/index.php/basicedu/index

\title{
Pengembangan Lembar Kerja Peserta Didik (LKPD) Dengan Menggunakan Model PJBL Di Sekolah Dasar
}

\author{
Lifda Sari ${ }^{1}$, Taufina ${ }^{2,}$ Farida $\mathbf{F}^{3}$ \\ Universitas Negeri Padang, Sumatera Barat, Indonesia ${ }^{1,2,3}$ \\ E-mail: lifda.sari1973@gmail.com ${ }^{1}$ taufina taufik@yahoo.co.id ${ }^{2}$ Faridafachrudin6@gmail.com ${ }^{3}$
}

\begin{abstract}
Abstrak
Penelitian ini bertujuan untuk menghasilkan Lembar Kerja Peserta Didik dengan model PjBL untuk siswa kelas V yang valid, praktis, dan efektif. Penelitian ini menggunakan penelitian pengembangan berdasarkan model 4D (Define, Design, Develop and Disseminate). Kevalidan Lembar Kerja Peserta Didik dilhat dari segi isi, bahasa, penyajian, kegrafikaan dan RPP, keseluruhan 3,59 dengan kategori sangat valid. Pratikalitas Lembar Kerja Peserta Didik dilihat dari respon pendidik dengan rata-rata 88,9\% dan efektivitasnya 86,7\%. Dapat disimpulkan bahwa Lembar Kerja Peserta Didik menggunakan model PjBL layak digunakan di kelas V SD.
\end{abstract}

Kata Kunci: bahan ajar, pembelajaran tematik, model PjBL

\section{Abstract}

This study aims to produce a Student Worksheet with a PjBL model for class $V$ students that is valid, practical, and effective. This study uses development research based on the 4D model (Define, Design, Develop and Disseminate). The validity of the Student Worksheets is seen in terms of content, language, presentation, graphic and lesson plans, overall 3.59 with a very valid category. The practicability of the Student Worksheets is seen from the educator's response with an average of $88.9 \%$ and its effectiveness at 86.7\%. It can be concluded that the Student Worksheet using the PjBL model is suitable for use in grade V elementary school.

Keywords: teaching materials, thematic learning, PjBL models

Copyright (c) 2020 Lifda Sari, Taufina, Farida F

$\triangle$ Corresponding author :

Address : Air Tawar Padang

Email : lifda.sari1973@gmail.com

ISSN 2580-3735 (Media Cetak)

Phone : 089531307164

ISSN 2580-1147 (Media Online)

DOI: $10.31004 /$ basicedu.v4i4.434 
814 Pengembangan Lembar Kerja Peserta Didik (LKPD) Dengan Menggunakan Model PJBL Di Sekolah Dasar - Lifda Sari, Taufina, Farida F

DOI: 10.31004/basicedu.v4i4.434

\section{PENDAHULUAN}

Setiap sekolah hendaknya mampu merancang dan mempersiapkan perangkat pembelajaran dengan matang serta selalu memperhatikan kebutuhan setiap siswa di sekolah yang bersangkutan. Perangkat pembelajaran yang diterapkan tidak terlepas dari LKPD yang digunakan dalam pembelajaran.

LKPD yang digunakan sangat menentukan pencapaian setiap kompetensi dasar yang ditetapkan. LKPD yang memenuhi kriteria baik akan melahirkan sebuah proses pembelajaran yang efektif (Ruzadiana et al., n.d.; Waluyo, Sa'dijah, \& Subanji, 2016). Namun sebaliknya, apabila LKPD kurang sesuai dengan kriteria maka yang akan lahir adalah berbagai permasalahan dalam pembelajaran. Selanjutnya LKPD merupakan segala bentuk bahan yang digunakan untuk membantu guru dalam melaksanakan proses pembelajaran (Zulkurnia \& Jaya, n.d.). Akan tetapi, LKPD yang digunakan hendaknya tidak hanya sekedar membantu proses pembelajaran namun melihat secara utuh ketercapaian kompetensi dasar yang dikembangkan. Mencapai kompetensi tersebut maka dirancanglah LKPD yang mengajak anak untuk aktif dalam kegiatan proyek (Haenilah \& Rusminto, 2017).

Berdasarkan observasi pada kelas V di SDN 39 Mata Air Padang Barat melalui pengamatan dan wawancara penulis selama dua minggu, ditemukan beberapa kebutuhan dan permasalahan utama. LKPD yang baik merupakan LKPD yang menggambarkan seluruh proses pembelajaran dan tidak berupa lembaran seperti LKS (Lembar Kerja Siswa), namun kenyataannya banyak LKPD yang belum menggambarkan seluruh proses pembelajaran dan LKPD berupa lembaran. Hal ini didukung dengan penelitian Sudrajat dan Surbakti (2017) (Sudrajat \& Surbakti, 2017). LKPD yang digunakan guru harus menarik perhatian siswa, namun nyatanya LKPD digunakan saat ini masih kurang menarik bagi siswa. Hal ini didukung dengan hasil studi yang dilakukan oleh Chao (2017) bahwa LKPD hendaknya dapat menarik minat siswa (Chao, 2017).

Dari wawancara yang di lakukan peneliti yang telah ditulis ulang oleh guru kedalam teks yang terdapat pada lampiran. Permasalahan yang ditemukan pada proses pembelajaran guru sudah menggunakan model pembelajaran yang baik namun belum mencapai hasil yang diharapkan. Dari kegiatan yang dilakukan sebagian siswa kurang memahami LKPD yang mereka gunakan. Telah diketahui bahwa dalam melakukan proses pembelajaran guru kurang mengajak siswa bekerja sama.

Mengatasi permasalahan di atas, perlu dilakukan pengembangan LKPD dengan menggunakan model yang menunjang keaktifan siswa sesuai kriteria penyusunan LKPD. Hal ini diperlukan karena buku siswa hanya memuat aktivitas belajar dan minim dalam menjelaskan materi pelajaran. Pengembangan LKPD yang baik haruslah memuat pengetahuan (fakta, konsep, prinsip, prosedur), keterampilan/ kemampuan, dan sikap yang harus dipelajari siswa dalam mencapai tujuan pembelajaran (Kusno, 2014). Selain itu, LKPD yang dikembangkan harus mengikuti perkembangan ilmu pengetahuan dan perkembangan zaman agar dapat memberikan ilmu 
yang terbarukan dan pengetahuan terkini sehingga bisa diterapkan siswa dalam kehidupannya.

Kurikulum 2013 pada kelas tinggi menuntut perencanaan dan pelaksanaan pembelajaran menggunakan model pengintegrasian sehingga model integrasinya adalah multidisipilinear walaupun pembelajarannya tetap menggunakan tematik terpadu dan ilmiah (scientific) tematik terpadu, dan tematik kelas IV, V, VI diperkuat dengan penerapan model pembelajaran discovery/inquiry learning, problem based learning dan project based learning. Untuk Sekolah Dasar (SD) disempurnakan lagi berdasarkan Peraturan Menteri Pendidikan dan Kebudayaan (Permendikbud) Tahun 2016 Nomor 22 tentang Karakteristik Pembelajaran menyatakan bahwa pendekatan ilmiah (scientific), tematik terpadu, dan tematik diperkuat dengan penerapan model pembelajaran discovery/inquiry learning, problem based learning dan project based learning (Permendikbud, 2016).

Pembelajaran yang dapat memfasilitasi siswa untuk berkarya baik secara individual maupun kelompok diantaranya adalah pembelajaran berbasis Proyek dalam standar proses dinyatakan bahwa untuk mendorong kemampuan siswa menghasilkan karya konsektual, baik individual maupun kelompok maka sangat disarankan menggunakan model pembelajaran yang menghasilkan karya kontekstual, maka sangat disarankan menggunakan model pembelajaran yang menghasilkan karya nyata yaitu model Project Based Learning. Menurut Amini dkk (2019) Project based learning didasarkan pada teori konstruktivisme dan merupakan pembelajaran siswa aktif (student centered learning), proses pembelajaran melalui project based learning memungkinkan pendidik untuk memberikan pembelajaran pengalaman langsung siswa (Amini, Setiawan, Fitria, \& Ningsih, 2019).

Model pembelajaran Project based learning (PJBL) yang menggunakan proyek/kegiatan sebagai tujuannya. Pembelajaran berbasis proyek (PJBL) memfokuskan pada aktivitas siswa yang berupa pengumpulan informasi dan pemanfaatanya untuk menghasilkan sesuatu yang bermanfaat bagi kehidupan siswa itu sendiri maupun bagi orang lain, namun tetap terkait dengan SK, KD kurikulum (Abdi, 2018). Uno (2010) menyatakan bahwa suasana yang mestinya tercipta dalam proses pembelajaran adalah bagaimana siswa berperan aktif dalam belajar (Uno, 2010).

LKPD dapat dikembangkan dengan adanya kreatifitas guru, seperti menciptakan buku yang berwarna dan dapat mengajak siswa berimajinasi. LKPD yang dapat digunakan dalam pembelajaran harus mengajak keaktifan siswa. Salah satunya dapat menggunakan LKPD dengan model yang sesuai yaitu dengan Model Project Based Learning $(P j B L)$ sehingga menimbulkan keaktifan siswa. Model Project Based Learning (PjBL) dipilih karena mempunyai daya tarik tersendiri bagi siswa karena mampu mengajak siswa untuk aktif (Gulay, 2015). Kelebihan dari model Project Based Learning $(P j B L)$ adalah memberikan pengalaman khusus pada siswa karena melibatkan siswa. Hal ini akan membuat kesan tersendiri kepada siswa sehingga akan lebih mudah masuk ke dalam ingatan ketika belajar. 
Berdasarkan permasalahan di lapangan sesuai wawancara guru, wawancara siswa, maka perlu dikembangkan LKPD yang sesuai dengan karakteristik siswa, menarik, dan interaktif, Salah satu solusi untuk permasalahan ini ialah dengan mengembangkan LKPD dengan model Project Based Learning (PjBL). LKPD ini dikembangkan dengan mengutamakan konten materi dan latihan soal yang memfasilitasi siswa dengan kegiatan proyek. Untuk itu, peneliti bermaksud mengangkat penelitian ini dengan judul Pengembangan LKPD Melalui Model Project Based Learning (PjBL) di Kelas V SD.

\section{METODE}

LKPD yang dikembangkan adalah LKPD untuk siswa sekolah dasar pada siswa kelas $\mathrm{V}$ dengan menggunakan model PjBL. LKPD yang dikembangkan digunakan merupakan penelitian pengembangan yang sering disebut Research and Development (R\&D). LKPD yang dikembangkan adalah LKPD valid dari segi bahasa, grafis, isi. Hal ini sesuia melaui proses/metode yang digunakan untuk memvalidasi dan mengembangkan produk (Creswell, 2016; Sugiyono, 2013).

Pelaksanaan penelitian dimulai dengan tahap define. Tahap pendefinisian bertujuan untuk menetapkan dan mendefinisikan syarat-syarat yang dibutuhkan dalam pengembangan LKPD. Tahap ini dilakukan dengan menganalisis tujuan dalam batasan materi pelajaran yang dikembangkan. Terdapat tiga langkah yang dilakukan dalam tahap pendefinisian, yaitu:
Analisis kebutuhan adalah melihat sejauh mana kebutuhan guru dan siswa terhadap LKPD melalui wawancara. Selanjutnya peneliti juga melihat dari segi kurikulum dengan menganalisis $\mathrm{KI}$, KD, dan Indikator pencapaian kompetensi materi yang terdapat dalam silabus yang dikeluarkan oleh BSNP tahun 2017. Kemudian membuat rumusan tujuan pembelajaran yang hendak dicapai oleh siswa. Beberapa hal yang perlu diperhatikan pada analisis kurikulum ini adalah analisis materi pada kelas V Tema 2 semester I.

Analisis juga dilakukan dengan menganalisi buku guru dan buku siswa. Analisis buku guru dilakukan untuk menelaah keterkaitan anatara indikator, tujuan pembelajaran yang hendak dicapai pada kelas V semester I di dalam tema 2. Dalam analisis ini dilihat permasalahan yang berkaitan dalam pengembangan LKPD. Analisis buku siswa dilakukan dengan menelaah materi beserta gambar yang terdapat dalam buku siswa. Subjek penelitian adalah LKPD dari buku siswa kelas V semester I pada tema 2. Hasil analisis ini dijadikan gambaran untuk mengembangkan LKPD siswa

Tahap perancangan (design) bertujuan untuk merancangan LKPD. LKPD dirancang sedemikian rupa sehingga siswa dapat belajar sesuai dengan kemampuan belajarnya masing-masing. Perancangan LKPD dilakukan dengan memilih format yang sesuai dengan format penelitian LKPD yang baik dan benar dengan memperhatikan kesesuai materi dan kurikulum. Pengembangan bahan ajar disusun sesuai tuntutan $\mathrm{KI}, \mathrm{KD}$, indikator dan tujuan pembelajaran yang 
mengaju pada komponen yang terdapat pada bahan ajar. LKPD ini juga memperhatikan cara penyajian materi pembelajaran tematik terpadu dengan model PjBL.

Tahap pengembangan (develop) bertujuan untuk menghasilkan bahan ajar yang valid, praktis, dan efektif. Tahap pengembangan meliputi:

1. Validitas isi (content validity), yaitu apakah bahan ajar yang dirancang sesuai dengan pembelajaran tematik.

2. Validitas konstruk (construct validity), yaitu kesesuaian komponen-komponen pengembangan yang sudah ditetapkan.

LKPD yang digunakan merupakan bahan ajar yang telah divalidasi oleh validator. Uji praktikalitas bahan ajar dilakukan menggunakan angket dan lembar observasi. Observasi dilakukan oleh dua orang pengamat, yaitu guru dan peneliti sendiri. Observer mengamati keterpakaian LKPD dalam proses pembelajaran dan mengisi instrumen observasi yang telah disiapkan. observer mengisi angket keterpakaian LKPD. Hasil angket ini dijadikan sebagai dasar untuk melakukan perbaikan terhadap LKPD yang dikembangkan. Aspek keterlaksanaan pembelajaran dilihat dari hasil pengisian lembar keterlaksanaan RPP oleh dua orang observer.

Efektivitas dilakukan untuk mengevaluasi bahan ajar telah efektif atau tidaknya. Hal yang dilakukan dengan melihat aktivitas dari pembelajaran. Melalui Tahap penyebaran penggunaan LKPD juga dilihat efektivitasnya subjek lain, misalnya di kelas lain, atau sekolah lain. Tujuannya adalah untuk menguji efektivitas penggunaan LKPD tersebut pada subjek yang berbeda. LKPD yang dikatakan efektif jika dapat memberikan hasil yang baik terhadap hasil belajar siswa. Peneliti melakukan penyebaran LKPD menggunakan model PjBL dalam skala terbatas yaitu di kelas V SDN 39 Padang Selatan.

\section{HASIL DAN PEMBAHASAN}

\section{Hasil Validasi}

\section{a. Validasi Isi}

LKPD yang dikembangkan harus melalui validasi ahli isi/materi diperlukan sebagai suatu bentuk evaluasi terhadap isi/materi serta penyajian produk yang telah dikembangkan. Data yang diperoleh berupa data kuantitatif dan kualitatif melalui angket yang diberikan peneliti kepada ahli. Angket di berikan kepada validator untuk melihat validas isi/ materi, dan produk yang dikembangkan. Berdasarkan perhitungan data angket yang diperoleh dari validasi diperoleh sebesar 3,48 dengan kategori sangat valid.

\section{b. Validasi bahasa}

LKPD juga dilihat dari segi bahasa sebagai evaluasi terhadap bahasa yang digunakan dalam LKPD yang sudah dikembangkan. Bahasa dalam LKPD harus efektif dan komunikatif sehingga mudah dipahami dalam pembelajaran. Validitas bahasa diberikan kepada ahli berupa angket yang menunjukkan perolehan 3,74 dengan kategori sangat valid.

c. Validasi aspek grafis

Grafis diperlukan sebagai evaluasi terhadap tampilan LKPD sehingga 
menarik perhatian siswa. Berdasarkan perhitungan data angket yang diperoleh dari validasi ahli grafis menunjukkan perolehan sebesar 3,48 dengan kategori sangat valid.

Tabel 1. Hasil Validasi Bahan Ajar

\begin{tabular}{|c|c|c|c|}
\hline No & $\begin{array}{c}\text { Aspek yang } \\
\text { Dinilai }\end{array}$ & $\begin{array}{c}\text { Nilai } \\
\text { Validasi }\end{array}$ & Kategori \\
\hline 1 & $\begin{array}{c}\text { Kelayakan } \\
\text { isi }\end{array}$ & 3,56 & Sangat Valid \\
\hline 2 & Kebahasaan & 3,74 & Sangat Valid \\
\hline 3 & Penyajian & 3,48 & Sangat Valid \\
\hline \multicolumn{2}{|c|}{ Rata-rata } & $\mathbf{3 , 5 9}$ & Sangat Valid \\
\hline
\end{tabular}

\section{Praktikalitas}

LKPD yang dikembangkan dengan model PjBL di Kelas V SD haruslah praktis dan efektif. Setelah dinyatakan praktis dan efektif, kemudian dilakukan dalam kelompok kecil one to one kemudian dilanjutkan dengan small group kemudian dilakukan uji efektifitas. Tingkat praktikalitas LKPD melihat sejauh mana peserta didik dapat menggunakan LKPD dengan baik. Pratikalitas yang diamati adalah keterlaksaan RPP, angket respon pendidik dan angket respon peserta didik terhadap pratikalitas bahan ajar. Hasil observasi saat uji coba di lapangan sesuai dengan perencanaan yang telah di buat dengan presentase $88,9 \%$ dengan kategori sangat praktis.

\section{Efektivitas bahan ajar}

LKPD dikatakan efektif apabila memberikan efek atau pengaruh baik terhadap pencapaian tujuan pembelajaran. Efektivitas peserta didik dilihat dari hasil belajar peserta didik dalam proses pembelajaran. Hasil analisis data terhadap aktivitas peserta didik ketika proses pembelajaran dengan memperolah hasil $86,7 \%$.

Hasil observasi terlaksananya RPP memperlihatkan bahwa pelaksanaan pembelajaran dengan menggunakan LKPD sudah berjalan dengan baik. Proses pembelajaran sudah terlaksana sesuai dengan langkah-langkah pembelajaaran dengan model PjBL. Kegiatan pembelajaran juga telah sesuai dengan waktu yang tersedia. Meskipun pada awalnya terdapat beberapa kegiataan yang tidak terlaksana dengan baik karena keterbatasan waktu dan beberapa siswa kurang terbiasa dengan kegiatan pembelajaran ini. Namun untuk pertemuan berikutnya guru telah mampu memperbaiki kekurangan-kekurangan yang terjadi dan mengarahkan siswa untuk mau mengeluarkan pendapat dan selalu bekerja dengan sungguh-sungguh.

Dalam hal ini, dapat diketahui bahwa LKPD yang dikembangkan dapat dengan mudah dilaksanakan oleh guru, artinya LKPD yang dikembangkan praktis. Sugiyono (2013) bahwa perangkat yang dikembangkan dapat dikatakan praktis, jika guru dapat menggunakan LKPD tersebut untuk melaksanakan pembelajaran secara logis dan berkesinambungan, tanpa banyak masalah. Dengan demikian, LKPD yang telah dikembangkan dapat digunakan sebagai contoh pada sekolah lain yang memerlukannya. 


\section{KESIMPULAN}

Berdasarkan pengembangan, uji coba, dan penyebaran yang dilakukan peneliti dapat menyimpulkan beberapa hal, sebagai berikut:

1. LKPD dengan model PjBL yang dikembangkan menunjukkan berada pada kategori sangat valid. Hal ini terlihat dari perolehan hasil validasi yang dilakukan validator ahli yaitu 3,59

2. LKPD yang dihasilkan dapat dinyatakan sangat praktis dari hasil analisis respon guru yaitu dengan rata-rata $88,9 \%$, dan aspek respon siswa dengan rata-rata $88,9 \%$.

3. LKPD yang dikembangkan dinyatakan efektif dilihat dari hasil aktivitas dan hasil belaja dengan nilai presentase ketuntasan $86,7 \%$.

Berdasarkan penelitian yang telah dilakukan, maka peneliti menyarankan hal-hal sebagai berikut:

1. Bagi peneliti, LKPD yang dikembangkan agar menjadi acuan dalam mengembangkan LKPD yang lain.

2. Bagi pendidik, agar dapat menggunakan LKPD yang telah dikembangkan secara valid dalam pembelajaran.

3. Bagi peneliti lain, agar dapat mengembangkan LKPD dengan model PjBL pada materi lain dan ruang lingkup sekolah yang lebih luas dengan situasi dan kondisi yang berbeda untuk mendapatkan hasil yang lebih sempurna.

\section{DAFTAR PUSTAKA}

Abdi, A. (2018). Penerapan Model Pembelajaran Project Based Learning (Pjbl) Untuk Meningkatkan Kreativitas Dan Hasil Belajar
Ipa Pada Siswa Kelas 5 Sd. Kalam Cendekia, Volume 6, Nomor 4.1, Hlm. 9-15, 6, 9-15.

Amini, R., Setiawan, B., Fitria, Y., \& Ningsih, Y. (2019). The Difference Of Students Learning Outcomes Using The Project-Based Learning And Problem-Based Learning Model In Terms Of Self-Efficacy. In Journal of Physics: Conference Series. Https://Doi.Org/10.1088/17426596/1387/1/012082

Chao-Fernandez, R., Román-García, S., \& ChaoFernandez, A. (2017). Online Interactive Storytelling As A Strategy For Learning Music And For Integrating Pupils With Hearing Disorders Into Early Childhood Education (Ece). Procedia - Social And Behavioral Sciences, 237(June 2016), 17-22. Https://Doi.Org/10.1016/J.Sbspro.2017.02.00 5

Creswell, J. W. (2016). Research Design: Pendekatan Metode Kualitatif, Kuantitatif, Dan Campuran. Sage Publication.

Gulay, B. (2015). Project Based Learning From Elementary School To College , Tool: Architecture. Procedia - Social And Behavioral Sciences, 186, 770-775. Https://Doi.Org/10.1016/J.Sbspro.2015.04.13 0

Haenilah, E. Y., \& Rusminto, N. E. (2017). Pengembangan Lkpd Berbasis Tematik Tema Merawat Hewan Dan Tumbuhan Siswa Kelas Ii Sd, (1).

Kusno. (2014). Peningkatan Aktivitas Peserta Didik Dalam Pembelajaran Tematik Terpadu Menggunakan Pendekatan Saintifik Di Kelas Iv. Jurnal Pendidikan Dan Pembelajaran, 2(1), 203.

Ruzadiana, L. M., Ertikanto, C., Unila, F., Sumantri, J., No, B., \& Lampung, B. (N.D.). Pengembangan Lkpd Dengan Model Pbl Sub Tema Macam-Macam Sumber Energi Kelas Iv Sd, (1), 1-15.

Sudrajat, A. A., \& Surbakti, A. (2017). Pengembangan Lkpd Tematik Berbasis Problem Based Learning Pada Materi 

Dasar - Lifda Sari, Taufina, Farida F

DOI: 10.31004/basicedu.v4i4.434

Peninggalan-Peninggalan Kerajaan Islam Di Indonesia Untuk Kelas V Sd.

Sugiyono. (2013). Metode Penelitian Pendidikan Pendekatan Kuantitaif, Kualitatif, Dan R\&D. Metode Penelitian Pendidikan Pendekatan Kuantitaif, Kualitatif, Dan $R \& D$. Https://Doi.Org/10.1007/S13398-014-01737.2

Uno, H. H. B. (2010). Model Pembelajaran: Menciptakan Proses Belajar Mengajar Yang Kreatif Dan Efektif. Jakarta: Bumi Aksara. Https://Doi.Org/10.1038/Cddis.2011.1

Waluyo, E., Sa'dijah, C., \& Subanji. (2016). Pengembangan Rpp Dan Lkpd Berbasis Realistic Mathematics Education Dengan Memerhatikan Beban Kognitif Siswa Materi Bangun Ruang Sederhana Kelas Iv Sd. Jurnal Pendidikan: Teori, Penelitian, Dan Pengembangan, 1(12), 2300-2306. Https://Doi.Org/10.17977/Jp.V1i12.8248

Zulkurnia, D., \& Jaya, M. T. B. S. (N.D.). Pengembangan Lkpd Berbasis Proyek Pada Siswa Kelas V Sd Muhammadiyah Kota Metro. 